\title{
Patterns of Epidural Venous Varicosity in Lumbar Stenosis
}

\author{
Jeong-Hyuk Ju, Ho-Gyun Ha, Chul-Ku Jung, \\ Hyun-Woo Kim, Chul-Young Lee, Jong-Hyon Kim \\ Department of Neurosurgery, Konyang University College of Medicine, Daejeon, Korea
}

Objective: Epidural venous varicosity (congestion of the epidural vein) is rarely introduced as an influential factor of clinical symptoms. However, there are several studies suggesting that epidural venous varicosity results in neurologic symptoms. We would like to highlight evidence that epidural venous varicosity results in neurologic symptoms and the relation between epidural venous varicosity and neural structure observed during the surgery. Based on our experiences, we also propose a new classification of epidural venous varicosity.

Methods: 29 patients with symptomatic lumbar stenosis received microsurgical decompression via partial hemilaminectomy. The authors retrospectively reviewed all recorded intraoperative pictures and categorized patterns of venous varicosities with relationship to neural structures.

Results: Type A is conditions in which epidural veins are dilated but located parallel to the nerve root on the lateral side of the nerve root and thus do not compress the nerve root. Type B is conditions in which varices are located on the anterior lateral side of the nerve root to compress the nerve root. Type $C$ is conditions in which varices are encircled around the nerve root and compressing the nerve root.

Conclusion: Epidural venous varicosity is observed in most lumbar stenosis patients with clinical symptoms. Of the types, the types of epidural venous varicosity compressing nerve structures were Type B and Type C. All epidural venous varicosities were removed regardless of classification during operations. Most patients showed relief in clinical symptoms after the operation. We thought to epidural venous varicosity as a factor that causes clinical symptoms of lumbar stenosis.

Key Words: Epidural space $\cdot$ Intermittent claudication $\cdot$ Radiculopathy $\cdot$ Spinal stenosis $\cdot$ Surgical decompression $\cdot$ Varicose veins

\section{INTRODUCTION}

Lumbar stenosis is a common disease in the elderly ${ }^{23)}$. The number of patients with lumbar stenosis complaining of low back pain, lower extremity pain and/or numbness, and neurogenic intermittent claudication (NIC) has increased yea$\mathrm{rly}^{11.16}$. The etiologies of symptomatic lumbar stenosis include nerve root compression and the disturbance of blood flow (ischemia or congestion of vessels), etc. which surround neural system $^{10,13)}$.

The factors caused nerve compression are hypertrophied ligamentum flavum, facet joints, and thickened lamina. We

- Received: April 13, 2012 - Revised: September 4, 2012

- Accepted: September 26, 2012

Corresponding Author: Ho-Gyun Ha, MD

Department of Neurosurgery, Konyang University Hospital, 685 Gasuwon-

dong, Seo-Gu, Metropolitan city Daejon 302-718, Korea

Tel: +82-42-600-9130, Fax: +82-42-600-8983

Email: hghns@kyuh.ac.kr often observed congestion of epidural veins (epidural venous varicosity) after removing the factors, intraoperativelly. Therefore, we have started this study which focuses on epidural venous varicosity.

Until now, epidural venous varicosity was rarely introduced as a factor that causes clinical symptoms ${ }^{16}$. However, there are several studies, $3,5,6,8,18,20)$ suggesting that epidural venous varicosity results in radiating pain through lower extremity, motor weakness, low back pain as well as $\mathrm{NIC}^{3,20)}$. Therefore, few authors insist that the removal of epidural venous varicosity is necessary during the operation ${ }^{5,8,20)}$. However, there is a controversy about how to manage the congestion of the epidural vein observed in operation field ${ }^{6,20)}$.

This study is originated from the hypothesis that epidural venous varicosity causes clinical symptoms, supported by numerous study reports and clinical experience ${ }^{2)}$. We would like to highlight evidence that epidural venous varicosity results in neurologic symptoms and the relation between epidural venous varicosity and neural structure observed during the surgery. Based on our experiences, we also propose a new classification of epidural venous varicosity. 


\section{MATERIALS AND METHODS}

\section{Characteristics of the patients}

Patients for this study were selected based on the definition of lumbar stenosis. We selected the patients with neurological symptoms in mild lumbar stenosis shown in radiologic imaging. The selected patients had undergone microscopic decompression via partial hemilaminectomy without discectomy under the diagnosis of lumbar stenosis between 2008 and 2011. As preoperative imaging, lumbar magnetic resonance imaging (MRI) and simple lumbar imaging (X-ray) were conducted to diagnose the patients' conditions. Those whose lumbar stenosis was caused by congenital factors, surgery, trauma, endocrine factors or musculoskeletal system related factors were excluded. Among lumbar stenosis patients, those with protruded or extruded discs were excluded and only those with bulging discs were included, in that protruded or extruded discs themselves may cause neurological symptoms. The reason we are making this exclusion is because even though nerve compression factor has higher contribution to cause clinical symptoms of lumbar stenosis than epidural venous varicosity, we wanted to find out effect of epidural venous varicosity on neural structure by minimizing nerve compression factor. The total number of patients was 29 including 16 males and 13 females. Their ages were variable from 48 years to 79 years and the average age was 62 years old. Preoperative symptoms of the patients were largely divided into four as follows; back pain, radiating pain of lower extremity, NIC, and lower extre-

Table 1. Patient profile

\begin{tabular}{ll}
\hline \hline Characteristics & \\
\hline total no. of patients & 29 \\
mean age (range) & $62(48-79)$ \\
male/female ratio & $16 / 13$ \\
presenting symptom (no. of patients) & \\
LBP $^{*}$ & 29 \\
Radiating pain $^{+}$ & 28 \\
NIC $^{+}$ & 27 \\
Motor weakness $^{\text {extent of decompression }}$ & 28 \\
1 level & 15 patients \\
2 level & 14 patients \\
intraop CSF leak & none \\
intraop neurologic injury & none \\
postop lumbar instability & none \\
\hline LBP: Lower back pain, ${ }^{+} \mathrm{NIC}:$ Neurogenic intermittent claudication
\end{tabular}

mity motor weakness (Table 1).

Postoperative clinical outcomes were assessed using the "Modified outcome grades" designed by Pappas ${ }^{17)}$. Grade I corresponds to cases in which patients are completely free from pain and Grade II corresponds to cases in which patients occasionally take acetaminophen. Grade I or II were considered to have successful operative outcomes. Those 29 patients underwent operations of total 43 levels. Of them, 15 patients $(52 \%)$ underwent an operation of a single level. We retrospectively checked video images recording entire operations to identify the relationship between nerve roots and epidural venous varicosity. In addition, we classified epidural venous varicosities in lumbar stenosis.

A p-value of less than 0.05 was considered statiscally significant. The data were statistically analyzed by one way ANOVA, and SPSS 12.0 for Windows (SPSS, Chicago, IL, USA) was used for statistical analysis.

\section{Surgical method}

Under general anesthesia, the patients were positioned in a 3/4 prone position so that the symptomatic side could be faced upward. Then, the patient's hip joint and knee joints were bent in a $3 / 4$ prone position with the trunk tilted around $3 / 4$ forward. The $3 / 4$ prone position was taken in order to exclude venous congestion caused by positioning. However, a prone position may result in epidural venous varicosity by compressing inferior vana cava. The $3 / 4$ prone posture is favorable in stopping intraoperative hemorrhage because venous congestion arisen from compressing of inferior vena cava is reduced. In addition, the operation field may become clearer in this position because bleedings occurred during operation are naturally drained to outside. As a consequence, epidural venous varicosity caused by lumbar stenosis could be accurately identified ${ }^{20)}$.

After performing microscopic partial laminectomy and partial medial facetectomy, the nerve root and the epidural vein were exposed by using microscissors and a microhook. The dissection of epidural venous varicosity was performed with caution, minimizing further injuries. Subsequently, the relationships between epidural venous varicosity and the neural structure (nerve root, theca sac) were examined. Every epidural venous varicosity exposed in the microscopic operative field of vision was carefully treated by electric cautery and excision.

\section{RESULTS}

\section{Patterns of epidural venous varicosity}

Epidural venous varicosity can be classified into four types 
based on the relationship between epidural venous varicosity (varices) and nerve structures. Type $\mathrm{N}$ is normal anatomical structures with no varices exist. Cases in which varices exist were divided into three types based on the appearance of varices. Type $A$ is conditions in which epidural veins are dilated but located parallel to the nerve root on the lateral side of the nerve root and thus do not compress the nerve root. Type $B$ is conditions in which varices are located on the anterior lateral side of the nerve root to compress the nerve root. Type $\mathrm{C}$ is conditions in which varices are encircled around the nerve root and compressing the nerve root (Fig. 1). Figure 2 shows a view of the relationship between the epidural venous varicosity and the nerve root observed in the operative field. Of the types, the types of epidural venous varicosity compressing neural structures were Type B and Type C. Among total 43 levels, Type $\mathrm{N}$ was observed in 2 levels, Type A in 7 levels, Type B in 24 levels and Type $C$ in 10 levels. Therefore, Type $\mathrm{B}$ was the most frequently observed with the percentage of $56 \%$ (Table 2).

\section{Postoperative clinical outcomes}

The patients' follow-up periods ranged from 2 months to 29 months with the mean of 8 months. Assessing the patients using "Modified outcome grade" devised by Papas ${ }^{17}$, the pa-
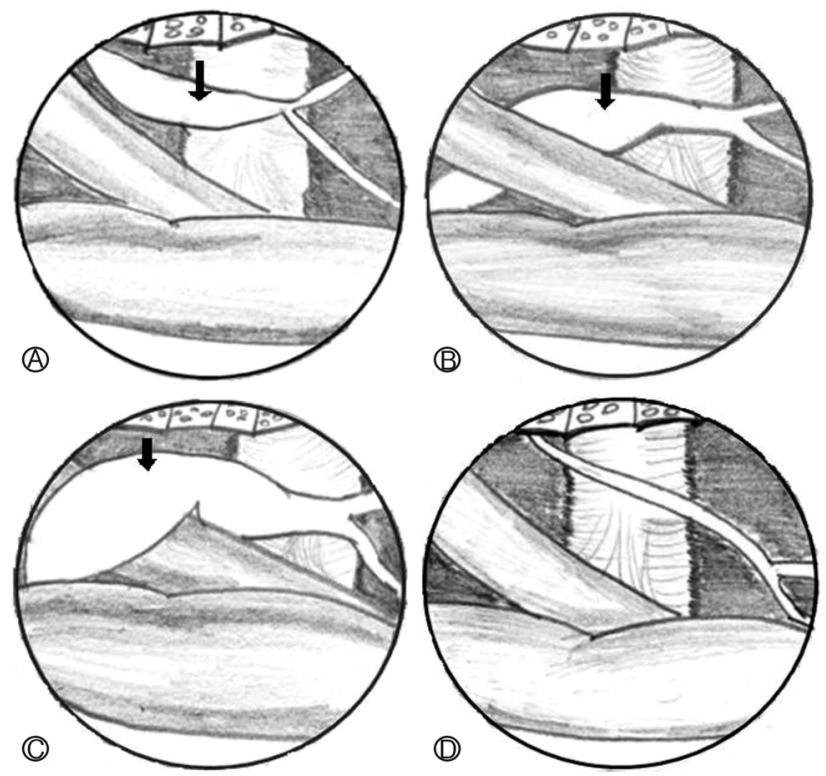

Fig. 1. Pattern of epidural varicosity in operative field (schematic illustration). Veins dilated but do not compress nerve root ( $A$; Type A). Veins dilated and located anterolaterally and compress nerve root (B; Type B). Veins dilated and encircled nerve root and compress it ( $C$; Type $C$ ). Type $N$ is normal anatomical structures with no varices exist (D). Venous varicosity (arrows) tients with Grade I (no pain) and Grade II (occasionally acetaminophen) attained $68 \%$ of the total successful outcome.

At least $70 \%$ of the patients showed the excellent or good recovery from their major preoperative symptoms. Motor weakness of lower extremity was improved in $86 \%$ of the patients as among these patients. NIC was improved to excellent recovery (89\%) and good recovery (11\%). Back pain (excellent $70 \%$, good $21 \%$, fair $6 \%$, poor $3 \%$ ) and radiating pain (excellent $71 \%$, good $11 \%$, fair $7 \%$, poor $11 \%$ ) symptoms were also significantly improved (Table 3 ).

All epidural venous varicosities were removed regardless of classification during operations. No intraoperative or postoperative complications were found. Also, no fusion or reoperation was performed during postoperative follow-up periods(Fig. 3).

Postoperative clinical outcomes were differed according to the types of epidural venous varicosity. All epidural venous varicosities were removed regardless of classification during operations. Of the total of 29 patients, four patients with combinations of different types of epidural venous varicosity were

Table 2. Classification of intraoperative patterns of epidural varicose vein

\begin{tabular}{llc}
\hline \hline Classification & Description & $\begin{array}{c}\text { Number of } \\
\text { level (total: 43) }\end{array}$ \\
\hline Type N & No demonstrable varicose veins & 2 \\
Type A & $\begin{array}{l}\text { Vein (s) dilated but do not } \\
\text { compress nerve root }\end{array}$ & 7 \\
& Vein (s) dilated and located ante- & 24 \\
Type B & rolaterally and compress nerve root \\
& $\begin{array}{l}\text { Vein (s) dilated and encircled } \\
\text { Type C }\end{array}$ & 10 \\
& nerve root and compress it & \\
\hline
\end{tabular}

Number of level per Type of epidural varicose veins

Table 3. Improvement of clinical symptoms of patients

\begin{tabular}{lcccl}
\hline \hline Symptom (n=29) & Excellent (\%) & Good (\%) & Fair (\%) & Poor \\
\hline $\begin{array}{l}\text { Motor } \\
\text { weakness (28) }\end{array}$ & $14(50)$ & $10(36)$ & $2(7)$ & $2(7 \%)$ \\
NIC (27) & & & & \\
LBP (29) & $24(89)$ & $3(11)$ & 0 & 0 \\
Radiating pain (28) & $20(70)$ & $6(21)$ & $2(6)$ & $1(3 \%)$ \\
\hline
\end{tabular}

${ }^{*} \mathrm{NIC}$ : Neurogenic intermittent claudication ${ }^{\dagger}$ LBP: Lower back pain The grade of clinical symptoms by White et al used for evaluation of clinical symptom following surgery: excellent: complete recovery, never have aware of symptom, Good: Return of full activities; $75 \%$ relief; no daily habitual medication, Fair: Patient able to work but at lighter capacity $50 \%$ relief or daily pain medication, Poor: No improvement or worsening; $25 \%$ or less subjective relief 

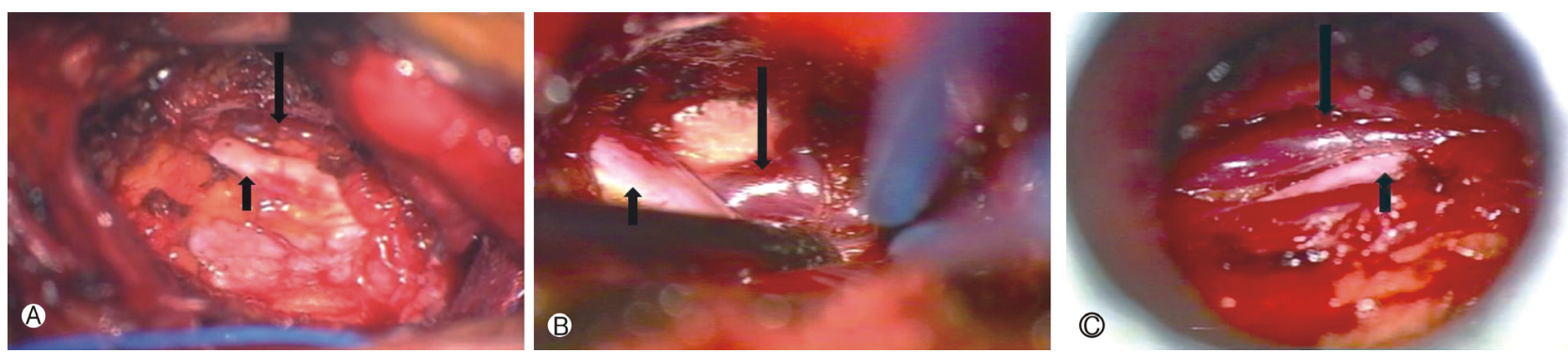

Fig. 2. Pattern of epidural varicosity in operative field. (A) represents Type $A$, (B) represents Type $B$, and (C) represents Type $C$. Among total 43 levels, Type $\mathrm{N}$ was observed in 2 levels, Type A in 7 levels, Type B in 24 levels and Type C in 10 levels. Nerve root (short arrows). Venous varicosity (long arrows)

excluded. The remaining 25 patients were assessed according to Pappas' outcome grades and successful postoperative outcomes were obtained in 50\% of Type A patients, $60 \%$ of Type B patients and $83 \%$ of Type C patients. Compared to other types, postoperative clinical outcomes were more successful in Type $\mathrm{C}$ epidural venous varicosity patients. However, it was not statistical significance $(p=0.508)$.

\section{DISCUSSION}

Lumbar stenosis is defined as a degenerative disease which causes narrowing of spinal canal. Surgical management of lumbar stenosis aims to remove the anatomical structures compressing neural structures and thereby relieving the compression.

However, it is commonly observed that the congestion of internal vertebral epidural venous plexus still remained even after the elimination of those structures in lumbar stenosis operation. The remained congestion of the internal vertebral epidural venous plexus is generally defined as an epidural venous varicosity $^{20)}$.

There are a number of researches regarding epidural venous varicosity. The prevalence of epidural venous varicosity is reported to be low. Recently, Slin'ko EI and colleagues ${ }^{20)}$ performed operations on 1091 patients with degenerative lumbar diseases. Of them, 48 patients showed epidural venous varicosity and thus they reported the prevalence of $4.4 \%{ }^{20)}$. However, those data are thought to be underestimated because epidural venous varicosities are easily accidentally ruptured during operation. For this reason, the authors tried to perform the operation with minimum injuries to epidural venous varicosity. As a result, epidural venous varicosities were observed during the operation in most patients with lumbar stenosis in this study.

Symptoms caused by lumbar epidural venous varicosity include NIC, lower extremity radiating pain, and motor weakness. The mechanism of the development of NIC has been studied in many researches ${ }^{6,7,18)}$. Some studies showed that changes
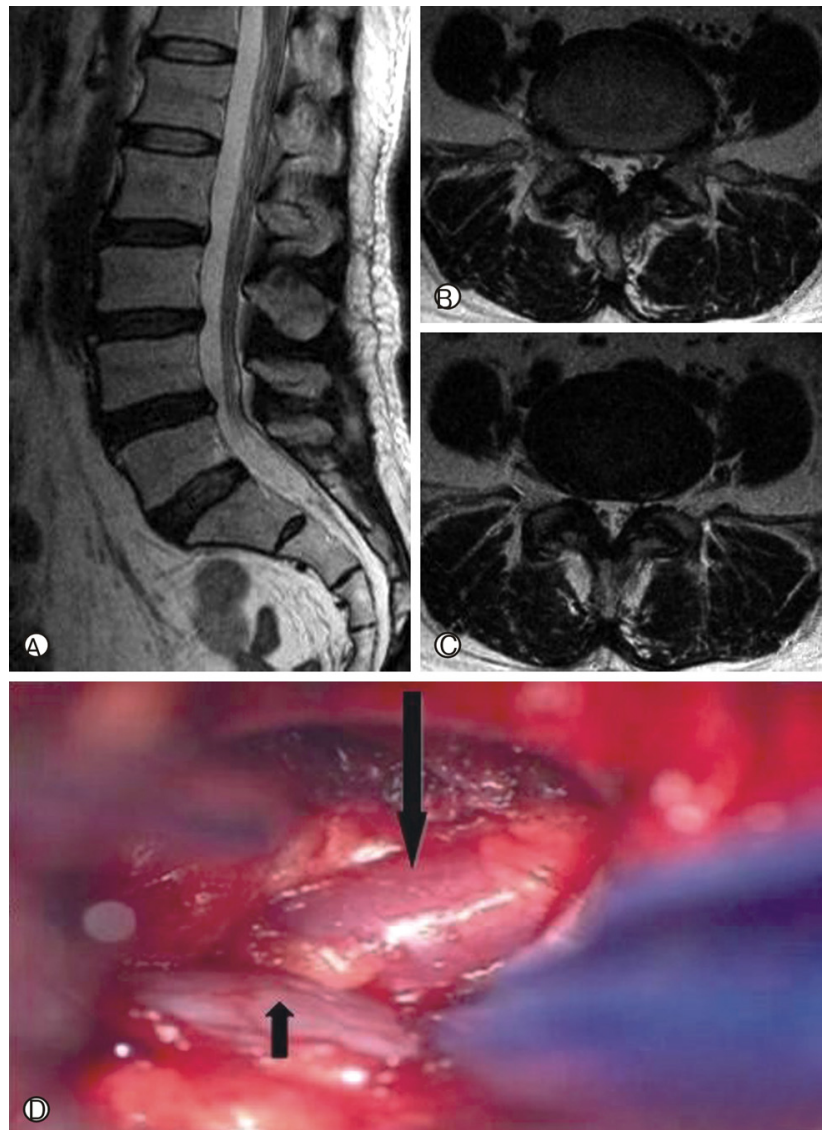

Fig. 3. Case illustration. A 50-year-old female attended to the hospital due to recent worsening mobility. On the Magnetic resonance imaging, hypertrophy of ligamentum flavum and annular tearing were shown (A, B, C). However, no other specific finding that may cause motor weakness was observed. We completely exposed the epidural lesion after removing ligamentum flavum and found an epidural venous varicosity compressing the $\mathrm{L} 5$ nerve root ventrally (D). Nerve root (short arrows). Venous varicosity (long arrows)

in postures led to changes in diameter of spinal canal ${ }^{10)}$. However, in the recent studies by Porter and colleagues ${ }^{19)}$ and Takahashi and colleagues ${ }^{21)}$, it was reported that epidural 
venous varicosity led to the development of NIC $^{19,21)}$. The veins surrounding the nerve root were primarily drained to the intervertebral foramen ${ }^{19,21)}$. If the venous drainage through intervertebral foramen was impaired, it resulted in the congestion of vein drained from conus medullaris. As a result, the subsequent reduction of blood flow led to the development of NIC ${ }^{19,21)}$. This is the evidence that NIC is closely related with blood flows. For these reasons, a higher blood flow is required to meet an increased oxygen demand in walking and insufficient blood flow consequently results in NIC.

Lower extremity radiating pain may also be arisen from epidural venous varicosity according to Genevay and colleagues ${ }^{6}$ Furthermore, epidural venous varicosity may cause other clinical symptoms such as motor weakness and myelopathy,4. Two mechanisms are described in order to explain the involvement of epidural venous varicosity in these clinical symptoms ${ }^{5,8,20)}$. The first mechanism is that venous congestion causes such clinical symptoms by compressing the theca sac and the nerve root. The second one is that a high pressure of epidural venous varicosity is transmitted to the perimedullary veins drained from the conus medullaris causing gradual myelopathy and neuropathy. Most authors consider that neurogenic symptoms are developed when the nerve root is compressed or stimulated by congested veins ${ }^{3,4,5,8,20)}$. Back pain caused by epidural venous varicosity is common, but the mechanism is not yet known $3,4,5,8,20)$.

Although there are numerous case studies reporting that an epidural venous varicosity results in clinical symptoms, most researchers have doubts in the clinical importance of epidural venous varicosity. In other diseases, the venous congestion is known to cause clinical symptoms. The most frequent symptom is trigeminal neuralgia. It is caused by the compression and stimulation of the trigeminal nerve by the petrosal vein ${ }^{1,7)}$. Sciatic neuralgia may also be developed, if lower extremity varices compresses the sciatic nerve ${ }^{9,22)}$. The aforementioned two cases support the fact that epidural venous varicosity is a sufficient source of neurogenic symptoms.

In addition, some authors published case reports about venous varicosity which was formed by other factors than degenerative diseases in lumbar spine and caused clinical symptoms. The symptoms were mainly radiculopathy or NIC. Epidural venous varicosity may be occurred in pregnancy, cardiomyopathy, portal hypertension, trauma and inferior vana cava thro$\mathrm{mbi}^{16)}$.

Diagnosing of epidural venous varicosity is difficult and generally overlooked. Computed Tomography (CT), MRI with or without enhancement ${ }^{3)}$, Magnetic resonance phlebography $(\mathrm{MRP})^{12,14)}$, CT myelography ${ }^{20)}$ can be used as diagnostic techniques. Although MRI is described as the most accurate technique in detecting epidural venous varicosity, it is difficult to identify epidural venous varicosity because of herniated disc which looks similar to epidural venous varicosity on MRI images at the same site $e^{5,7,19)}$. The limitation of this study lies on the fact that other diagnostic studies were not performed apart from preoperative MRI.

Other authors diagnosed epidural venous varicosities using the aforementioned test methods and classified the types in diverse methods. Slin'ko EI and colleagues ${ }^{20)}$ classified epidural venous varicosity using preoperative MRI and venography ${ }^{20}$. Varices were classified segmentary varices, local varices, extensive varices ${ }^{20)}$. Hanley and colleagues ${ }^{8)}$ divided epidural venous varicosity into three types based on radiological findings and anatomical pathology ${ }^{8}$. Manaka and colleagues ${ }^{14)}$ classified abnormal epidural venous varicosity seen on MRP into five types, associated with $\mathrm{NIC}^{14)}$. Morikawa and colleagues $^{15)}$ classified epidural veins based on the patterns of contrast enhancement on $\mathrm{MRI}^{15}$.

However, there are no papers classifying accurate types of epidural venous varicosity based on the observation during operations. We propose a new classification system designed to describe the relationship between the nerve root and the epidural venous varicosity. The classification system is based on the observation from the operative field and there are four patterns. We thought that clarifying the relationship between nerve roots and epidural veins is more important than identifying the names of individual veins. It is worthwhile for surgeons to understand the relationship between nerve roots and epidural venous varicosity.

As it was mentioned above, more successful outcome was shown in type $\mathrm{C}$ than other types. However, it was not statistical significance. It is difficult to understand an accurate relationship between types of varice and neurological symptoms because of numerous related variables that cause neurologic symptoms.

Many reports describe appropriate managements for each type of epidural venous varicosity. Hanley and colleagues ${ }^{8)}$ removed epidural varices using electric cautery or excision in all five patients with symptoms caused by epidural venous varicosity ${ }^{8)}$. After the operation, all patients were relived of symptoms $^{8)}$. According to published papers, in the majority of cases, the interventions led to a positive clinical result with resolution of the neurological symptoms ${ }^{20,24)}$. In this study, removal of epidural venous varicosity was done in consideration of lumbar epidural venous system anatomy. Among epidural veins, anterior longitudinal veins and intervertebral veins are related with nerve roots. Therefore, only these veins were removed, not retrocorporeal veins. By preserving the retrocorporeal veins, obstruction of venous drainage due to the removal of the epidural venous varicosity could be avoided. In our study, NIC was alleviated in most patients as well 
as other symptoms.

\section{CONCLUSION}

Epidural venous varicosity is observed in most lumbar stenosis patients with clinical symptoms and epidural varices were classified into four types based on the relationship between neural structures and epidural varices in microscopic operation field. Of the types, the types of epidural venous varicosity compressing neural structures were Type B and Type C. All epidural venous varicosities were removed regardless of classification during operations. Most patients were relieved of clinical symptoms after operation. We thought to epidural venous varicosity as a factor that causes clinical symptoms of lumbar stenosis. Still, further studies are necessary to firmly establish the diagnosis and treatment of epidural venous varicosity.

\section{REFERENCES}

1. Adams CB: Microvascular compression: an alternative view and hypothesis. J Neurosurg 57:1-12, 1989

2. Campbell DN, Liechty RD, Rutherford RB: Traumatic thrombosis of the inferior vena cava. J Trauma 21:413-415, 1987

3. Demaerel P, Petre C, Wilms G, Plets C: Sciatica caused by a dilated epidural vein: MR findings. EurRadiol 9:113-114, 1999

4. Dickman CA, Zabramski JM, Sonntag VKH, Coons S: Myelopathy due to epidural varicose veins of the cervicothoracic junction. Case report. J Neurosurg 69:940-941, 1988

5. Zimmerman GA, Weingarten K, Lavyne HM: Symptomatic lumbar epidural varices. report of two cases. J Neurosurg 80:914918, 1994

6. Genevay S, Palazzo E, Huten D, Fossati P, Meyer O: Lumboradiculopathy due to epidural varices: two case reports and a review of the literature. Joint Bone Spine 69:214-217, 2002

7. Hammer A, Knight I, Agarwal A: Localized venous plexi in the spine simulating prolapse of an intervertebral disc: a report of six cases. Spine (Phila Pa 1976) 28:E5-E12, 2003

8. Hanley EN Jr, Howard BH, Brigham CD, Chapman TM, Guilford WB, Coumas JM: Lumbar epidural varix as a cause of radiculopathy. Spine (Phila Pa 1976) 19:2122-2126, 1994

9. $\mathrm{Hu} \mathrm{MH}$, Wu KW, Jian YM, Wang CT, Wu IH, Yang SH: Vascular compression syndrome of sciatic nerve caused by gluteal varicosities. Ann VascSurg 24:1134, 2010
10. Kobayashi S, Takeno K, Miyazaki T, Kubota M, Shimada S, Yayama T, et al: Effects of arterial ischemia and venous congestion on the lumbar nerve root in dogs. J Orthop Res 26: 1533-1540, 2008

11. Kobayashi S, Uchida K, Takeno K, Baba H, Suzuki Y, Hayakawa $\mathrm{K}$, et al: Imaging of cauda equine edema in lumbar canal stenosis by using gadolinium-enhanced MR imaging: experimental constriction injury. AJNR Am J Neuroradiol 27:346-353, 2006

12. LaBan MM, Wang AM, Shetty A, Sessa GR, Taylor RS: Varicosities of the paravertebral plexus of veins associated with nocturnal spinal pain as imaged by magnetic resonance venography: a brief report. Am J Phys Med Rehabil 78:72-76, 1999

13. Lipetz JS: Pathophysiology of inflammatory, degenerative, and compressive radiculopathies. Phys Med RehabilClin N Am 13: 439-449, 2002

14. Manaka M, Komagata M, Endo K, Imakiire A: Assessment of lumbar spinal canal stenosis by magnetic resonance phlebography. J OrthopSci 8:1-7, 2003

15. Morikawa M, Sato S, Numaguchi Y, Mihara F, Rothman MI: Spinal epidural venous plexus: its MR enhancement patterns and their clinical significance. Radiat Med 14:221-227, 1996

16. Paksoy Y, Gormus N: Epidural venous plexus enlargements presenting with radiculopathy and back pain in patients with inferior vena cava obstruction or occlusion. Spine (Phila Pa 1976) 29:2419-2424, 2004

17. Pappas CTE, Sonntag VKH: Lumbar stenosis in the elderly. NeurosurgQuarterly 4(2):102-112,1994

18. Pekindil G, Yalniz E: Symptomatic lumbar foraminal epidural varix. Case report and review of the literature. $\mathrm{Br} \mathrm{J}$ Neurosurg 11:159-160, 1997

19. Porter RW, Ward D: Caudaequina dysfunction. The significance of two-level pathology. Spine (Phila Pa 1976) 17:9-15, 1992

20. Slin'ko EI, Al-Qashqish II: Surgical treatment of lumbar epidural varices. J Neurosurg Spine 5:414-423, 2006

21. Takahashi K, Olmarker K, Holm S, Porter RW, Rydevik B: Double-level caudaequina compression: an experimental study with continuous monitoring of intraneural blood flow in the porcinecaudaequina. J Orthop Res 11:104-109, 1993

22. Hu KH, Wu KW, Jian YM, Wang CT, Wu IH, Yang SH: Vascular compression syndrome of sciatic nerve caused by gluteal varicosities. Ann VascSurg 24(8):1134, 2010

23. Wee SB, Jung SS, Park KS, Kuh SU: Surgical treatment of degenerative lumbar spine disease in geriatric patients over 70 years old: a review of two decades. Korean J Spine 5(3):161-166, 2008

24. Wong CH, Thng PL, Thoo FL, Low CO: Symptomatic spinal epidural varices presenting with nerve impingement: report of two cases and review of the literature. Spine (Phila Pa 1976) 28:E347-E350, 2003 